\title{
PENGARUH LABEL PASUPATI PADA PRODUK DUPA TERHADAP MINAT BELI KONSUMEN
}

Made Ika Kusuma Dewi ${ }^{1}$

Fakultas Dharma Duta,

Institut Hindu Dharma Negeri Denpasar

\begin{abstract}
Balinese religious ceremonies are an integration of sublime values that have evolved from one tradition to the next. Cultural rituals will require the objects used to carry out the ritual process. These objects that can be used as a business opportunity in every religious ceremony such as the items needed are incense, flowers, and Canang. the emergence of incense labeled Pasupati with many benefits produce many diverse variations in incense products and can be said that the incense labeled this pasupati can compete in market competition.

The results of the research is that without the innovation and innovative of the entrepreneurs (distributors) will not be the incense labeled this post. The significance of the label of the Pasupati in the incense products include economic distributors want to benefit as much and for incense only give positive energy instead of giving atman or spirit to the incense. There is a significant influence on incense labeled this pasupati in the intention of buying consumers. The advice of researchers is expected to add insight to incense labeled Pasupati and as a reference in religious sciences.

Keywords pasupati label on incense products, purchase intention to buy consumers
\end{abstract}

\section{PENDAHULUAN}

Bali dikenal dengan budaya adi luhung karena keunikan dan kekahasannya yang tumbuh dari spirit agama Hindu, sehingga dikatakan bahwa agama Hindu sebagai jiwa kebudayaan Bali begitu pula sebaliknya kebudayaan Bali bernafaskan agama Hindu. Kehidupan sosial keagamaan dan adat budaya masyarakat Hindu di Bali sangat sulit untuk dibedakan, sebab dalam melaksanakan aktivitas keagamaannya selalu bertindak secara religi. Hal ini dibuktikan bahwa masyarakat Hindu adalah masyarakat yang religious. Mengacu pada keyakinan diatas, masyarakat Hindu Bali dalam menciptakan suatu benda, terutama yang terkait dalam keyakinan agama disertai

${ }^{1}$ kusuma_dewi@ihdn.ac.id 
dengan suatu upacara ritual. Terlebih lagi benda tersebut akan disakralkan, mulai dari mencari bahan baku, pembuatannya, sampai upacara pasupati yang dilaksanakan pada hari yang baik. Upacara tersebut memiliki makna tersendiri dimana upacara pasupati bermakna menghidupkan atau memberi jiwa.

Secara umum pasupati atau pemasupatian dapat dimaknai sebagai sebuah proses pensakaralisasian benda, sehingga benda yang akan dipasupati diyaknini memiliki kekuatan magis atau supranatural. Kekuatan yang ada dalam benda setelah dipasupati inilah diyakini dapat memberikan perlindungan, keselamatan, kekuatan bahkan dapat menghalau segala macam penyakit dan segala rintangan. Pasupati adalah aspek Siva sebagai pengikat hidup atau pemberi hidup. Maka tidak salah, jika masyarakat Hindu di Bali melakukan prosesi pemasupatian agar benda yang dipasupati memiliki roh atau jiwa untuk hidup. Siva sebagai Pasupati yang tanpa awal dan akhir, pencipta alam semesta, entitas tunggal yang memiliki berbagai wujud dan bentuk, dan memahami hal itu orang akan mendapatan kedamaian.

Belakangan ini marak beredarnya produk dupa dengan berlabel pasupati, penggunaan label ini tentu memiliki maksud dan tujuan yang beragam. Dari sudut ekonomi tentunya produk agar laku dan mendapatkan keuntungan sebanyakbanyaknya. Label pasupati dipandang sebagai salah satu media promosi yang ampuh di zaman ini agar konsumen tertarik dengan produk yang dipasarkan terlebih di Bali. Setelah benda berupa dupa tersebut dipasupati dimohonkan pula kekuatan magis dan membuktikan bahwa telah mempunyai kekuatan dari Ida Sang Hyang Widhi Wasa yang dapat diartikan pengujian kekuatan maupun kesucian diberkahi oleh Sang Hyang Pasupati. Adapun setelah dipasupati, amat diyakini oleh masyarakat bahwa dupa tersebut memiliki kekuatan suci Ida Sang Hyang Widhi Wasa atau Ida Hyang Pasupati. Keyakinan yang tebal pada masyarakat setelah dupa tersebut diupacarai akan diberkahi kekuatan sakti para dewa sebagai manifestasi Ida Sang Hyang Widhi Wasa. Pada proses pasupati orang melakukan upacara tersebut menyatu sehingga proses penghadiran dewa yang dikehendaki kekuatannya benar-benar hadir dan mengisi benda yang akan dipasupati tersebut. Kemunculan produk dupa berlabel pasupati merupakan hal yang baru yang menarik minat konsumen membeli dupa tersebut. Peningkatan penjualan dengan memberi label pasupati sebagai daya tarik menjadi dasar penelitian ini untuk mengetahui pengaruh label pasupati terhadap minat beli konsumen. 
Banyaknya konsumen yang membeli produk dupa dengan label pasupati ini tentu menjadi suatu fenomena tersendiri yang menarik untuk dipelajari. Atas dasar tersebutlah, peneliti tertarik untuk mengetahui serta mempelajari adanya pengaruh label pasupatí terhadap minat beli konsumen.

\section{METODELOGI PENELITIAN}

Sumber data dalam penelitian ini merupakan data primer. Data primer adalah data yang diperoleh dengan survei lapangan yang menggunakan semua metode pengumpulan data orginal (Kuncoro, 2013). Data Primer mengunakan bentuk verbal atau kata-kata yang diucapkan secara lisan, gerak-gerik atau perilaku yang dilakukan oleh subjek yang dapat dipercaya.

Penelitian ini menggunakan metode pengambilan sampel. Sampel dalam penelitian ini adalah konsumen beragama Hindu di Bali. Metode pemilihan sampel bersifat non-probability sampling yaitu purposive sampling. Penentuan jumlah responden ini didasari dari Roscoe (1975), dalam Sekaran (2016), di mana jumlah sampel minimal adalah sebanyak 10 dikalikan jumlah item instrumen pertanyaan kuesioner. Jumlah item instrumen pertanyaan kuesioner dalam penelitian ini adalah sebanyak 19 pertanyaan. Meskipun demikian, penulis mengambil sampel penelitian minimal sebanyak 100 responden. Penelitian ini dilakukan di Desa Blahbatuh Kecamatan Blahbatuh, Gianyar dimana peneliti melihat adanya pasar yadnya di Desa Blahbatuh tersebut yang menjual alat-alat upakara serta banyaknya ibu-ibu memakai dupa berlabel pasupati untuk melakukan kegiatan upacara baik kecil maupun upacara besar.

\section{PEMBAHASAN}

Kemampuan produsen dalam membuat suatu produk untuk menarik minat konsumen seperti dupa berlabel pasupati ini sangat terkait dengan niat beli konsumen untuk dapat menarik minat pembeli. Hasil penelitian yang didapatkan yaitu bahwa tanpa adanya inovasi dan inovatif dari para pengusaha (distributor) tidak akan adanya dupa berlabel pasupati ini. Makna pencatuman label pasupati pada produk dupa ini meliputi dari segi ekonomi distributor ingin meningkatkan penualan produknya.

\section{Pencantuman Label Pasupati Pada Produk Dupa \\ Setiap masyarakat memiliki serangkaian ritual kebudayaan yang mendefinisikan budayanya. Setiap ritual budaya akan membutuhkan benda-benda (artefak) yang digunakan untuk melaksanakan proses}


ritual. Setiap upacara keagamaan umat Hindu misalnya, benda-benda yang dibutuhkan adalah dupa, bunga dan canang. Para distributor dupa akan melakukan inovasi agar produk dupanya dibeli dan digunakan oleh konsumen sehingga mendapatkan keuntungan sebesarbesarnya. Adanya dupa pasupati menjadi simbol didalam masyarakat sehingga dupa pasupati merupakan ikon dalam ibadat agama. Persepsi konsumen terhadap sesuatu termasuk bagaimana cara berpikir, percaya dan bertindak ditentukan oleh lingkungan budaya sekitar konsumen serta kelompok yang berhubungan dengan konsumen dan seluruh pengaruh kelompok sosial pada perilaku beli konsumen diawali dari kebudayaan dimana konsumen itu tinggal. Kebudayaan mengimplikasikan sebuah cara hidup yang dipelajari secara total dan diwariskan. Hal ini mengandung arti bahwa kebudayaan tidak hanya mencangkup tindakan yang berdasarkan naluri. Kebudayaan mempengaruhi perilaku pembelian karena budaya menyerap kedalam kehidupan seharihari. Budaya menetapkan apa yang didengar, dimakan, dimana tinggal dan kemana bepergian. Karena budaya mempengaruhi bagaimana seseorang membeli dan menggunakan produk dan mendapatkan kepuasaan terhadap produk-produk tersebut.
Makna Yang Terkandung Pada Dupa Berlabel Pasupati

Pasupati adalah aspek Siva sebagai pengikat hidup atau pemberi hidup. Maka tidak salah, jika masyarakat Hindu di Bali melakukan prosesi pemasupatian agar benda yang dipasupati memiliki roh atau jiwa untuk hidup. Siva sebagai pasupati yang tanpa awal dan akhir, pencipta alam semesta, entitas tunggal yang memiliki berbagai wujud dan bentuk, dan memahami hal itu orang akan mendapatan kedamaian. Olehnya mistisime Sivaistik memberikan pemaknaan yang dalam tentang Pasupati tersebut sebagai sebuah proses penyatuan antara pasu dan pasupati. Dimana untuk mencapai kemanunggalan tersebut, terlebih dahulu kita melepaskan segala sifat hewani kita yang ada dalam diri. Makna yang demikian, tidak banyak umat yang mengetahui, justru pasupati akhir-akhir ini hanya dijadikan label produk. Hal ini bukan tidak mungkin akan membawa implikasi bias makna ajaran agama dari sakral menuju profanisme. Bukan berarti produk tersebut tidak baik, bukan pula pelaku usaha produk tersebut salah. Akan tetapi yang perlu dipahami, seyogyanya pelaku usaha yang bergerak pada sektor itu benar-benar melakukan proses pemasupatian sebagai mana mestinya terhadap produk yang dihasilkan, agar benar-benar memberikan vibrasi postif bagi konsumen, terlebih jika 
menggunakan produk tersebut dengan seketika sifat kebinatangan konsumen lenyap dan mencapai kemanunggalan.

Janganlah hanya demi uang mengorbankan sisi fundamental ajaran Hindu. mengutip wacana Swami Vivekananda;

"Uang tidak dapat diandalkan, tidak juga nama, tidak juga intelek. Hanyalah cinta kasih yang dapat diandalkan".

Dalam wawancara pada pemilik usaha dupa pasupati kaori, kaori memaparkan bahwa berawal dari pengalaman anak dimana pada saat bayi suka menangis dengan alasan yang tidak jelas, ingin menanyakan hal tersebut pada dokter tapi urung dilaksanakan karena tidak adanya tanda-tanda sakit. "Berceritalah narasumber pada instruktur yoga. la pun menyarankan untuk menyalakan sebelas batang dupa di depan rumah sebelah kiri. Saya ikuti saran beliau. Kemudian beliau transfer energi, tak lebih dari 15 menit anak saya tak menangis lagi". Nah lantas saya kepikiran begini, bagaimana kalau ada kejadian yang serupa menimpa ibu-ibu lainnya, pasti mereka kebingungan. Untuk itu saya mendiskusikan hal tersebut dengan instruktur-instruktur yoga saya tersebut. Apakah bisa saya membuat dupa yang sudah dipasupati untuk menghalau energi negatif. Pasupati dalam konteks ini memberi mantra-mantra gaib pada setiap dupa. Akhirnya dengan berbagai pertimbangan, diijinkan untuk menyebarluaskan produk. Ternyata respon masyarakat positif. Mereka pun membuktikan sendiri saat menyalakan 11 batang dupa Pasupati ini, anak mereka pun jarang menangis lagi.

Dupa ini mampu menghalau aura negatif yang datang dari luar. Sederhananya, dupa ini sebagai sarana keselamatan. Dupa Pasupati Kaori ini pun kami pisahkan dari dupa-dupa Kaori yang lain dan kami beri tanda gelang Tridatu lambang dari tri murti yaitu Dewa Brahma, Dewa Wisnu, dan Dewa Siwa untuk keseimbangan alam dan warna dupa berlabel pasupati inipun merah, putih dan hitam. Dapat dikatakan bahwa label pasupati pada produk dupa hanyalah energi positif yang dihantarkan dari jarak jauh. Pada kemasan dupa inipun sudah diberikan penjelasan bahwa dupa ini telah dipasupati dan diadhistana (diberkati) berdasarkan metode Yoga Tantra yang gaib dan melalui titah rahasia Hyang Shakti dengan perantara Dokter Gede Kamajaya dan Ibu Putu Rahmadewi (Praktisi Yoga Tantra).

Pemasaran Dupa berlabel pasupati inipun menggunakan Alat-alat komunikasi massa dimana dalam komunikasi massa terdapat media cetak dan media elektronik. Media cetak ini meliputi surat kabar, majalah, dan tabloid sedangkan media elektronik meliputi radio dan televisi. Distributor dupa berlabel pasupati inipun 
sangat gencar menayangkan iklan produk dupa berlabel pasupati ini ke media cetak maupun media elektronik. Dimana fungsi dari media massa ini adalah fungsi memberikan informasi, fungsi memberi Pendidikan dan fungsi untuk mempengaruhi. Dengan adanya iklan tersebut siapapun yang melihat, membaca ataupun mendengarkan iklan dupa berlabel pasupati ini akan menghasilkan efek yang akan membuat konsumen ingin membeli dupa berlabel pasupati ini. Selain dari komunikasi massa adanya komunikator yang memberikan testimoni yang baik dan merasakan hasil saat menggunakan dupa berlabel pasupati ini juga berpengaruh dalam minat beli konsumen.

\section{Pengaruh Label Pasupati Pada Produk Dupa}

\section{Terhadap Minat Beli Konsumen}

Hipotesis kasus ini adalah :

Ho : Tidak ada hubungan antara label pasupati pada produk dupa dalam minat beli konsumen ibu-ibu desa Blahbatuh, kecamatan Blahbatuh kabupaten Gianyar. Ha : Ada hubungan antara label pasupati pada produk dupa dalam minat beli konsumen ibu-ibu desa Blahbatuh, kecamatan Blahbatuh kabupaten Gianyar.

Dasar pengambilan keputusan :

Berdasarkan perbandingan chi-square hitung dengan chi-square tabel : Jika Chi- square Hitung $<$ Chi-Square tabel maka Ho diterima.

Jika Chi-Square Hitung > Chi-Square tabel maka Ho ditolak.

Chi-Square hitung lihat pada output SPSS bagian PEARSON CHI-SQUARE yaitu 54.207a.

Sedangkan Chi-Square tabel bisa dihitung pada tabel Chi-Square dengan memasukan :

Tingkat Signifikan $\alpha=5 \%$ Pada SPSS, tingkat signifikan ditetapkan sebesar $5 \%$ yang tentu akan mengubah ChiSquare tabel.

Derajat Kebebasan $(\mathrm{df})=2$

Berdasarkan rumus $\mathrm{df}=$ (jumlah baris - 1) $x($ jumlah kolom -1) maka $\mathrm{df}=(2-1) \mathrm{x}$ $(31)=2$, lihat output SPSS yang menyatakan angka 2. Dari tabel didapat Chi-Square tabel adalah 5,9915. Dapat disimpulkan bahwa Chi-Square Hitung > Chi-Square tabel $(54,207>5,9915)$, maka Ho ditolak.

Berdasarkan Probilitas (signifikan)

Jika probilitas $>0,05$, maka HO diterima

Jika probilitas < 0,05 maka HO ditolak

Sesuai dengan pengaruh label pasupati pada produk dupa $(x)$ dalam minat beli konsumen ibu desa Blahbatuh (y) dengan menggunakan Teknik analisis data chi-square dengan program data SPSS. Jika hasil signifikan 0,05 maka hipotesis 0 ditolak, sedangkan hasil penelitian ini adalah dengan nilai signifikasi uji Asymp.Sig sebesar 0,000 
kurang dari 0,05 sehingga HO ditolak. Dapat disimpulkan bahwa ada pengaruh nyata dan signifikan label pasupati pada produk dupa (x) dalam minat beli konsumen ibu desa Blahbatuh (y).

\section{SIMPULAN}

\section{Simpulan}

Adanya pengaruh label pasupati pada produk dupa terhadap minat beli konsumen sangat dipengaruhi oleh beberapa hal: 1) fungsi komunikasi massa yaitu adalah fungsi mempengaruhi khalayak dimana iklan dupa berlabel pasupati ini sangat sering di iklankan melalui media cetak maupun media elektronik sehingga para konsumen yang melihat dan mendengarkan akan ingin mencari tahu apakah produk dupa berlabel pasupati ini benar-benar bermanfaat. 2) adanya manfaat yang dirasakan konsumen terhadap suatu produk akan menghasilkan komunikasi dimana konsumen yang telah mendapatkan manfaatnya akan menceritakan pengalamannya kepada khalayak baru dan khalayak yang belum menggunakan dupa berlabel pasupati tersebut akan membeli dupa berlabel pasupati dan mencoba produk tersebut.

\section{DAFTAR PUSTAKA}

Ardianto, Elvinaro

dkk.2014. Komunikasi Massa. Bandung: Simbiosa Rekatama Media
Dharmmesta, Basu Swastha. 2010. Perilaku Konsumen. Jakarta: salemba

Ferrinadewi,Erna. 2008. Merek dan Psikologi Konsumen: Implikasi pada Strategi Pemasaran. Yogjakarta : Graha Ilmu

Gulo, W. 2002. Metode Penelitian. Jakarta: PT Grasindo.

Kuncoro, Mudrajad. 2013. Metode Riset Untuk Bisnis dan Ekonomi. Jakarta: Erlangga.

Littlejohn, Stephen W, 2009. Teori Komunikasi Theories of Human Communication edisi 9. Jakarta: Salemba Humanika.

Luwiyanto. 2006. Upacara Pasupati Prasasti Lontar di Bali Tinjauan

Semiotik dalam Rangka Fungsi.

Magistra No. 90 Th. XXVI, Desember 2014

Morissan. 2013. Teori Komunikasi Individu Hingga Massa, Jakarta: Prenada media Group

Peter, J. Paul dan Olson, Jerry C. 2008. Perilaku Konsumen dan Strategi Pemasaran. Jakarta: Salemba

Sarwono, Jonatan. 2006. Analisis Data

Penelitian Menggunakan SPSS.

Yogyakarta: Andi

Sekaran, U. 2006. Metode Penelitian Bisnis. Jakarta: Salemba Empat Sri Suprapti, Ni Wayan. 2010. Perilaku 
Konsumen "Pemahaman Dasar dan

Aplikasi dalam Strategi Pemasaran".

Denpasar $\backslash$ : Unudpress

Swarsi. 2008. Upacara Pasupati sebagai

Media Sakralisasi. Denpasar: Paramita

Tamburaka, Apriadi. 2012. Agenda Setting

Media Massa. Jakarta: PT Raja

Grafindo Persada

Wiana, I Ketut. 2000. Arti dan Fungsi Sarana

Persembahyangan. Surabaya :

Paramita 